\title{
Economic Assistance, a Direct Support to the Families in Need. Concepts and Realities
}

\author{
Blerina Xhakolli (Reci) \\ University "Aleksander Moisiu" Durrës \\ Faculty of Education, Departament of Psycology \\ blerina.xhakolli@gmail.com
}

Doi:10.5901/mjss.2014.v5n6p347

\section{The Albanian Family Yesterday and Today}

In our society the family has been structured and always surrounded by "protection walls" to continue the contingency and the conservation of the traditions created in years. The co-habitation of two or more generations in one family has always been an accepted reality, never to be changed. Therefore, the family has been considered as one of the most conservative and untouchable institutions, having its own well-defined social hierarchy.

The extended family is defined to be a group of 3 or more generations, living together within one living premises or very close to one-another (A. Giddens). The Albanian society has the same modality: Three generations (children, parents and grandparents). In the newly created families it is not that often to encounter with this modality. This change has been effected by the individualism and not only. Men and women are taking longer time of reflection before they get married.

It is not a requirement that an extended family should live under the same roof, but most of the time the members of a family live near one-another and they work together in groups. The family living under the same roof is called "extended family, in the sense of habitation", whereas the families, whose members have the same role and are depended on one-another it is called "functionally extended". Nowadays, families do not conserve these definitions, but move outside them to follow their social and economic interests and not necessarily living together.

The Albanian modern society is facing continuous changes in the relationship between man and the family. This social triangle seems to become every day more fragile and undefined. The relation between man and these two institutions of the moral standards are undergoing major changes especially during the recent years. The balance within the social triangle individual-family-society are becoming very delicate and fragile. This is clearly noticed when we look at different social phenomena sustaining the lack of stability within the family, which is reflected in the chaotic social life of the Albanian society.

Most of the social concerns faced by our society are result of the abnormal situations within many families, lack of stability of the family members, which inevitably affect the stability of our society.

From the moral and social point of view, the Albanian family and society is going through a very complicated and chaotic process of changing their traditional nature and adapting to the modern role and nature.

The changing processes within the Albanian family show the lack of stability and the difficulties faced to carry out its traditional social functions, what makes the situation worse are the continuous attacks against the past, the typology and against the old relationships.

The old charm of the traditional Albanian family, the cell defining behavior, progress and one's personality, is fading away. In the past the family reputation, the attributions, and the political personality of the family were decisive for the individuals future. In now days this interfering mission of the family is no longer functioning.

\section{Economic Support in Albania. Concepts and Realities}

The economic support, the basic concepts for the good functioning of this scheme, its legal frame, the groups and the categories of the families benefiting from this Economic Support, the functional principles of this support, the role, the type and the benefiting ways for the families in need and the impact is has, have undergone major changes during the last 20-ty years. The concept of Economic Support is relatively new to Albanian society, it is only "twenty years". Before the 90-ties the "rich" Albania did not have poor families in need for economic support. The state exercised its power in a certain way to cover the obvious poverty. It is in the society best interest and a right defined by law that every individual 
has the right to live with dignity and not to be discriminated. We are all equal before the law. The social services for the people in need, especially the economic support, it's not just a mere financial problem that can be resolved with the approval by state of the allocated budged to support these individuals and families, because the society does not base its evaluation of an individual on the financial means of living. Actually, the real problem is the physical needs and meeting the basic life needs for these families. In order meet these needs the state should interfere with the assistance of social policies, which will build up the relation need-individual-policy.

\section{The Purpose of the Economic Support}

The main purpose of the Economic Support, as shown by its name, is to support and assist individuals and families in need, which are facing financial constrictions and cannot meet their basic needs of living.

\section{The Concept of Poverty and Unemployment}

What is the concept of poverty? What would be the best social strategy to minimize or even eliminate it?

The family in need is considered to be the one that does not get enough material and/or financial income from the economic activities or other programs of the social assistance.

There are several opinions related to the definition of poverty. Some opinionates consider poor a person that does not have enough incomes to meet his/her basic needs.

On the other side the World Bank has given another definition of poverty:

Poverty is the drastic decrease of the welfare and involves many dimensions: low incomes and unemployment, in order to provide for the basic material and financial needs to survival, low level of education and medical services, lack of water supply and sewage systems, physical insecurity, lack of expression freedom, lack of possibilities for e better life.

It is noticeable from both definitions that poverty has to do with the lack of meeting the basic life conditions, those considered vital such as: the need for nutrition, clothing and lodging. To be considered poor one should not have any source of income.

One of the peculiarities of poverty is that it is always companied by some demographic characteristics like: the poor families have the tendency to be composed from many members, mostly children, which means many unemployed members. Furthermore, poor families do not have proper access to the basic services such as in schools, health care centers, phones, water, hygiene etc. What makes the situation worse is the fact that these families have never been informed about the access to many services that would help them to improve their living conditions because most of these families live in very remote areas of the country and the interest for improving their welfare is minimal. The definition of the poverty are different, but in order to benefit from the financial support scheme the family should not have any sources of income, in this case we will have to deal with absolute poverty as the family is not able to meet its basic needs (according to the definition of the absolute poverty). On the others side the amount of financial support benefited by these families is not enough, and this is clearly seen in the perception they have about it and in the impact it has in facing everyday needs.

The central element of poverty is "not enough income". There is a relation between the poverty and the unemployment. Unemployed are considered to be: "all adults, specified to keep the population economically active, who during the referred period meet these requirements: are unemployed, willing to work, and looking for a job. So basically the main source of the incomes is work, and on the other side the source of, poverty is the difficulty to find a good and stable job in an employment market so fragile and insecure. Therefore these are the factors determining the low welfare not only of the individuals but of the whole society. The importance of this scheme helped me to identify two social issues: poverty and the relation of the poverty with unemployment. What should be kept in mind is the fact that the scheme of Financial Support is directly connected with the trends of poverty. The state is responsible to guarantee and defend the welfare of its citizens. In a certain way, the state through the Social Services, the institution monitoring and super visioning the program of Financial Support has made several attempts to resolve problems related to the society welfare and to decrease the poverty.

\section{How does the Financial Support Scheme Functions in Albania}

The social and economic changes in Albania during the 90-es challenged the state institutions to compile a program of Financial Support within the structures of Ministry of Labor, and a mean to assist the individuals and families in need. It the very beginning, year 1993, the Financial Support had a great flux. During the last two decades Financial Support has 
undergone different changes, but what is more important is that it has expanded, by assisting new groups to present themselves as a group in need.

During these years, this scheme has evolved and has changed the way it considers the scale of poverty. During the first years the scale of poverty was so high that it seemed it was applying the absolute poverty. Nevertheless, since this scheme includes only certain groups and not all of them, that means that these groups get compared with one another by applying other principles, which means that this scheme has been build up not based upon the needs but upon the legislation, which has changed during the years.

\section{The Legal Basis of the Financial Support}

In order to have this program function properly it was necessary to have the legal basis on which it would operate as well as all the other indicators for its continuance.

In 1993, the financial support program begun to function based on the Law no.7710.dated.18.05.1993 "On the Support and Social Services" this law was on power until 2005.

The MCV.no.787 dated 14.12.2005: The delineation and the classification of the criteria, procedures and the amount of the financial support:

- Directive no.338/3 dated.10.03.2006 "On the application of the MCV no.787 dated 14.12.2005" on the Delineation and the classification of the criteria, procedures and the amount of the financial support.

- Directive no.497 dated: 06.03.2006" On the calculation of the incomes deriving from the agricultural and breeding production"

- MCV no. 65 dated .09 .08 .2006 "On the defense of the families in need from the increase of the electricity supply price" MCV no. 512.dated .31 .05 .2006

The legislation supporting this scheme has changed several times, but even though there has never been a limit on the benefiting term of a family from this scheme. There are families that have been benefiting from this scheme since its very beginning and continue to do so. During the interviews with heads of families at the Financial Support Office, some of them proudly say that they are brought up with the help of this scheme. In other words, I do not consider as positive impact the immunity of scheme for its success. Time after time there have been proposals and taken decisions that some aspects of this scheme should change. The success of this scheme depends on many factors such as:

- $\quad$ Administration of the scheme by the social administrators.

- The criteria of the families benefiting.

- The procedures to be applied by a family in order to become part of it etc.

The always present criticism to this scheme is the fact that it is very easy for families, which are not in real need of financial support, to benefit from it. The local government officials plan important role, directly or indirectly, in defining the beneficiary families. The risk of misuse with the scheme remains high. In order to avoid this misuse several monitoring structures in local and central level of power have been established. The monitoring structures are very important for the well-functioning of the Financial Support system as well as for successfully meeting its ultimate goal: the reduction of poverty and the distribution of support means to families, beneficiaries of this scheme. Nevertheless, I would like to add here that the distribution of this financial support has not had an positive impact in reducing the poverty level. Every day we see more and more families not being able to meet the basic needs. This evidence shows that this scheme does not reduce to poverty but it only "softens" its impact.

Some changes in the legal basis and in the administration of this scheme would affect it positively.

The service of Financial Support was established when the poverty rate was very high. It was necessary for the government to take measures and intervene to change the critical situation of the society. The radical changes in every field had a high cost.

The last initiative has been to offer, for the first time, to the families in need not only financial support but a monthly material assistance.

The criteria to benefit from the scheme of financial support will be based on en evaluation system on the need, considering the family components, the incomes as well as the benefits from social defense, possible incomes from the assets such as land, herd and other socio-economic variables related to the status of poverty. The changes foresee an additional payment based on the family structure, on the children, who attend the compulsory educational system. This change aims to encourage the families in need to bring their children to school. A data base, for the local government units, with the information on the beneficiary and families who ask to benefit from this scheme, will be compiled. This data base will facilitate the job of different state agencies at local level to better comply the legal obligations. The registration will increase the data accuracy, and will assure the exchange of information on timely manners in order to define the real 
poverty status of the applicant family.

Evaluating the fact that the financial support has been funded so far by the state budged and drawing from other countries experience, it has been proposed that the financial support should be conditioned by participation in services or employment, which will help in better targeting the individuals in need, the reduction of poverty level and changing the financial support scheme from passive to active.

Every Albanian government has considered this scheme as a heavy burden for the budged and have done everything possible to reduce the number of beneficiaries or the amount to be given to them by putting rather strange benefit requirements, including here asking the applicants to submit a great number of documents.

\section{Recommendations and Conclusions}

\subsection{Recommendations on what the Financial Support should reconsider and review:}

- The structure of the Financial Support, including the benefited amount in relation with the poverty limit.

- The beneficiary rules, e.g. the granting criteria and the responsibilities of the beneficiaries, such as the information requested by the beneficiary on the connection between benefiting from the Financial Support and the steps taken for the employment.

- The evaluation techniques of the applicants, in order to avoid any misuse of the scheme.

- The removal from the beneficiaries list of the families abusing with the Financial Support.

- Increase of the benefit level.

- Improvement of the evaluation system of the applicant families.

- Conditioning the beneficiaries with community services.

\subsection{Conclusions:}

- The Financial Support has helped in "softening" of the poverty but not in eliminating it.

- It is time to find new ways of assisting the people in need, because those one applied so far have not been very effective.

- Compiling new policies, which main focus will be the groups in need.

- Cooperation between all the participating actors in order to have accurate studies in evaluating the community needs.

- Increasing the scheme transparency and effectiveness.

\section{References}

Merita (Vaso) Xhumari "The Process and the Institutions of the Social Policies", ABC, Third Publication, Tiranë 2009

Dhembo Eliona dhe Irida Agolli "Social Policies and Social Welfare" albPAPER, Tiranë 2010

Law no.10399, dated. 17.03.2011 "On the Social Services and Assistance"

Law no.9355, dated. 10.03.2005 "On the Social Services and Assistance"

Verdict no 1053 dated.23.04.2008

http://www.instat.gov.al

http://web.worldbank.org 